\title{
Effects of Analogy Instructional Strategy, Cognitive Style and Gender on Senior Secondary School Students Achievement in Some Physics Concepts in Mubi Metropolis, Nigeria
}

\author{
UGWUMBA AUGUSTINE OKORONKA ${ }^{1}$, BITRUS ZIRA WADA ${ }^{2, *}$ \\ ${ }^{1}$ department of Science Education, Adamawa Sate University, Mubi, Nigeria \\ ${ }^{2}$ government Junior Secondrary School, Muva, Mubi North, Nigeria \\ *Corresponding author: Wadazy48@Gmail.com
}

Received June 06, 2014; Revised August 16, 2014; Accepted September 03, 2014

\begin{abstract}
The study investigated the effects of analogy instructional strategy, cognitive style and gender on senior secondary school students achievement in some physics concepts in Mubi Metropolis, Nigeria. Instructional strategy at two levels was crossed with two levels of cognitive style and two levels of gender which served as moderator variables. A 2x2x2 matrix, pre-test, post-test, control group, quasi-experimental design was employed for matching the factors. Data were collected using two validated and reliable instruments namely: the Cognitive Style Test (CST) and Physics Achievement Test (PAT). A total of 82 senior secondary school two (SS 2) students from four schools took part in the study. Data were analysed using mean, t-test, factorial analysis of variance (ANOVA) and Least Significant Difference (LSD) Post Hoc Mean Comparison Test. The results showed significant main effect of treatment on achievement and significant interaction effect on achievement when cognitive style was crossed with gender. The more effective treatment was the analogy instructional strategy. Analytical female students and nonanalytical male students were homogeneous, while the analytical male and non-analytical females were not in the same homogeneous group.
\end{abstract}

Keywords: Analogy instructional strategy, Cognitive Style, Gender, Achievement in Physics

Cite This Article: UgWUMBA AUgustine OKORONKA, and BITRUS ZIRA WADA, "Effects of Analogy Instructional Strategy, Cognitive Style and Gender on Senior Secondary School Students Achievement in Some Physics Concepts in Mubi Metropolis, Nigeria.” American Journal of Educational Research, vol. 2, no. 9 (2014): 788-792. doi: 10.12691/education-2-9-13.

\section{Introduction}

The emphasis on science and technical education by the Nigerian government is well documented [1]. This is because of its perceived contribution in making Nigeria to become self reliant, great and dynamic economy through producing scientists for national development and the training of its citizen to be self-reliant [2]. In order to achieve these objectives, senior secondary school and technical college curricular demanded that all science and technical students must offer physics as a subject because of its importance in the study of science and technology disciplines.

In spite of the fact that these cannot be achieved without the knowledge of physics, studies by [3,4] and [5] identified several factors such as inappropriate selection of instructional strategies by the teachers, inadequate instructional facilities, poor attitudes of students towards science and technical subjects among others as militating against the attainment of the objectives of Science and Technical Education in Nigeria. One of the key factors identified which is the focus of this study is the teacher related factor specifically, the instructional strategies adopted by technical teachers to teach the subject. The teacher is known to be the fulcrum about which the entire business of curriculum implementation in school revolves. His attitude and personality combined with his choice of instructional strategies and resources determine not only the interest and attitude of the learner but also the aspirations and achievement in school subjects [6]. National Business and Technical Examination Board (NABTEB) Chief Examiner's report attributed the low performance of students in National Technical Certificate (NTC) examination to the inappropriate use of instructional strategies by teachers [7]. It has been observed by these researchers that the current technique adopted by most secondary school teachers to teach physics in Mubi metropolitan schools is the conventional lecture method. Reference [8] observed that the continuous use of the lecture method to teach students some abstract concepts like atom, current, voltage and others reduce their ability to grasp the meaning than when they are taught using instructional strategies like analogy that build on their pre- existing ideas. Reference [9] 
observe that knowledge is actively constructed by the learner on the grounds of constructs already available to him/her in the mind.

A key factor in the teaching and learning process derived from teacher related factors is the strategies used in imparting knowledge to the learner. According to Reference [10], knowledge of available techniques is a valuable asset towards effective teaching. Success in teaching generally depends to a large extent on the appropriate selection and application of a teaching strategy for each subject matter.

The need to improve students' performance through effective teaching and learning strategies at various levels of education is one of the major concerns of educationist today. According to Reference [11] research in education aims at developing better ways of teaching so as to help the students learn and perform well in school.

In an attempt to address the problem of students' difficulties in understanding science and technology, $[12,13]$ and [11] suggested analogy as one of the instructional strategies that could be used for the teaching of abstract or difficult concepts in science and technology. This is because analogy instructional strategy which is based on Novak's theory of human constructivism sees production of new knowledge as a human construct. Thus analogy plays a critical role in a constructivist framework for learning science. In such framework, students develop by learning progressively more sophisticated mental models of science concepts. Often, these concepts represent complex, hard to visualize systems with interacting parts [9]. In physics, for instance the atom, current, voltage, resistance among others cannot be seen. Therefore, the use of analogy can pave way for the expansion of the target concept thereby helping to create understanding for the learner.

Electricity as one aspect of physics had been identified by students as difficult and abstract in nature due to its mathematical content [14]. But [15] observed that difficulty is a formed attitude which can be broken by adopting the most appropriate instructional strategy.

Cognitive style of the students and gender had been selected as moderating variables in this study. Cognitive style categorization has been reported to have strong relationship with achievement in science ([16-20]). Similarly, gender has been implicated through research findings as a factor which affects achievement in mathematics and science ([21] \& [22]). Cognitive style is a term used in cognitive

psychology to describe the way individuals think, perceive and remember information or their preferred approach to using such information to solve problem. This study focused on field independent (FI)-field dependent (FD) model of cognitive style because it is the dimension that is said to possess the greatest potential for application to education problem ([23]). FI-FD dimension of cognitive style is concerned with the ability to perceive a part of stimulus as distinct to its surroundings through active and analytic as oppose to global processes [24]. FI students tend to be more analytical and better able to restructure an abstract subtle aspect of a problem in contrast to FD students who have their social skills, attitudes, perceptions and qualities strongly influence by their physical and social background [19]. The way individuals prefer to receive information and process them is affected by methods of teaching. Some scholars like $[13,25,26]$ among others have confirmed the influence of cognitive styles on students performance in science. Gender which may be referred to as socio-cultural stratification of individuals as male and female is also a moderating variable which may affect achievement in physics. There is a general belief that men perform better than women especially in science based subjects like physics [(21]). The need to find new techniques in the classroom which can be combined with students' cognitive style and gender to bring about understanding of difficult or abstract physics concepts and ultimately lead to improved performance of learners informed this study.

\subsection{Purpose of the Study}

The need to find specific instructional techniques that could mediate difficulty/abstraction of certain concepts/topics in physics informed this study. The purpose of the study therefore, was to determine the effects of analogy instructional strategy alone and in conjunction with individual difference variable of cognitive style and gender on the achievement of senior secondary school students in some difficult/abstract physics concepts.

\subsection{Research Hypotheses}

The study was guided by seven null hypotheses tested at 0.05alpha level as stated below:

1. There is no significant main effect of treatment on achievement.

2. There is no significant main effect of cognitive style on achievement.

3. There is no significant main effect of gender on achievement.

4. There is no significant interaction effect of treatment and cognitive style on achievement.

5. There is no significant interaction effect of treatment and gender on achievement.

6. There is no interaction effect of cognitive style and gender on achievement

7. There is no interaction effect of treatment, cognitive style and gender on achievement.

\section{Methodology and Instrumentation.}

The study adopted a pre test, post test, non randomized control group, quasi-experimental design in which treatment (at two levels) was crossed with cognitive style (at two levels) and genders (at two levels). The subjects consisted of 82 senior secondary (SS) 2 physics students (37 boys and 45 girls) with varied cognitive styles (44 FI) and (38 FD). Intact classes were used and four senior secondary/technical schools located within Mubi North local government area of Adamawa state were selected. Two schools were used for each of the experimental conditions namely analogy instructional strategy and lecture method.

Basic quantities of electricity and electrical circuits consisting of the following concepts Current, Voltage, resistance series and parallel circuits. The selection was based on the fact that these are the fundamental concepts of electricity which students always find difficult due to 
their abstractness and lots of calculations involved ([14]). Two validated and reliable instruments were used for data collection, namely the Cognitive Style Test (CST) and Physics Achievement Test (PAT).

The study was conducted in four senior secondary schools that offer physics in the National Business and Technical Examination Board/National Examination Council (NECO)/West African Examination Council (WAEC) in Mubi town. The schools are made up of two government owned and two privately owned schools. Mubi is a town located in the north eastern part of Nigeria. According to [27], Mubi lies geographically between latitude $10^{0} 30^{1}$ and $10^{0} 05^{1}$ of the equator and between longitude $13^{0} 10^{1}$ and $13^{0} 30^{1} \mathrm{E}$ of Greenwich meridian. The population for this study consisted of all senior secondary (SS2) physics students in Mubi town.

\subsection{Techniques}

Four senior secondary schools were purposively selected. Two of the

schools were coded group A for "experimental” (group taught using analogy instructional strategy) and another two coded group B for "control” (group taught using lecture method). Data were collected through the use of Physics Achievement Test (PAT) which consisted of 25 multiple choice questions constructed by the researchers but, patterned after NECO and WAEC standardized test items. Pre test was administered to the students by the researchers before treatment to determine their entry behavior. Post test was administered after the treatment. Cognitive style test was equally administered to the students by the researchers to categorize them into FI and FD styles.

\subsection{Validation of the Instruments}

The instruments (CST and PAT) were validated by two Senior Lecturers from the Science Education Department Adamawa State University, Mubi who are experts in science education for face, construct and content validity. All the suggestions and recommendations of the valuators were considered to produce the final draft of the instrument.

\subsection{Reliability of the Instruments}

Split half method was used in estimating the reliability of the PAT. The instrument was administered to 82 SS2 science students of Schools with similar characteristics as those used for the study. Each student's score was split into two (odd and even) numbers and correlated using the Pearson's Product Moment Correlation Coefficient Statistic. A correlation coefficient of 0.97 for internal consistency was obtained. The Spearman Brown formula for correlation yielded a coefficient of 0.98. The CST adopted is a modified version of the Siegel Cognitive Style Test which has been systematically adapted and modified in Nigeria over the years. For instance, the model by [28,29,30] and [20]. References [29] and [30] each revalidated the test and calculated Pearson Product
Moment Correlation Coefficient, ranging from $\mathrm{r}=.71$ to $\mathrm{r}$ $=.72$ respectively. These were considered satisfactory for the purpose of the present study.

\section{Results}

Post-test achievement test in physics (ATP) scores were subjected to 2x2x2 factorial analysis of variance (ANOVA) and t-test. The results from Table 1 show that students were homogeneous academically before the treatment (pre-test) with mean scores of 10.95 and 11.31 for groups $\mathrm{A}$ and $\mathrm{B}$ respectively. The results shown in Table 2 also revealed that calculated value of $t$ is 0.021 and critical value is 1.99.This result implies that there is no significant difference in the academic achievement of groups A and groups B before the treatment. After the treatment (posttest), groups A had mean score of 69.71 while group B had 48.71. This gave mean differences of 58.76 and 37.40 for group A and group B respectively as shown in Table 1. The results shown in Table 3 reveal that there is significant difference in physics achievement between those students taught using analogy instructional strategy and those who were taught using lecture method $(\mathrm{df}=, 80 \mathrm{t}$ $=0.02, \mathrm{P}=0.000<0.05$ )

There is significant main effect of instructional strategy on students' achievement in physics $(\mathrm{F}=82.44, \mathrm{P}=$ $0.0000<0.05$ ) as shown in Table 4 The results in Table 3 also show that there is no significant main effect of cognitive style on students' achievement in post test $\operatorname{PAT}(\mathrm{F}=1.50, \mathrm{P}=0.2247>0.05)$.

Also, students' gender has no significant main effect on achievement in the post test PAT score $(\mathrm{F}=0.59, \mathrm{P}=$ $0.4449>0.05$ ).

When students' cognitive style was considered with gender, there was a significant interaction effect on students' achievement $(\mathrm{F}=6.09, \mathrm{P}=0.0159<0.05)$. Also, when students' cognitive style was considered along with instructional strategy (treatment), there was no significant interaction effect on achievement $(\mathrm{F}=0.00, \mathrm{P}=0.9627>$ 0.05). Similarly, when students' gender was considered with treatment, there was no significant interaction on achievement $(\mathrm{F}=0.04, \mathrm{P}=0.8362>0.05)$. Finally, when students' cognitive style was considered along with gender and the instructional strategy, there was no significant interaction effect on achievement in post test (PAT) $(\mathrm{F}=0.00, \mathrm{P}=0.9830>0.05)$.

Table 4, which is the Least Significant Difference (SLD) Post-Hoc Comparison Test, shows that FI, female students and FD male students with mean scores of 63.05 and 61.93 respectively are homogeneous. On the other hand, FI male and FD female students with mean scores of 58.90 and 54.04 respectively are non homogeneous. Therefore they can be compared.

Table 1. Pre Test and Post Test Mean Scores of Group A and B

\begin{tabular}{ccc|cc}
\hline & \multicolumn{2}{c|}{ Pre test } & \multicolumn{2}{c}{ Post test } \\
\hline Treatment & $\mathrm{N}$ & Mean & Mean & Mean Difference \\
\hline Analogy(A) & 41 & 10.95 & 69.71 & 58.76 \\
Control (B) & 41 & 1 & 48.71 & 37.40 \\
\hline
\end{tabular}

Table 2. T-Test of Pre-Test Scores Between Group A and B

\begin{tabular}{|c|c|c|c|c|c|c|}
\hline Treatment & N & Mean & SD & df & t & Significant (2- tailed) \\
\hline Analogy (group A) & 41 & 69.71 & 10.25 & 80 & 0.02 & 1.99 \\
\hline Control (group B) & 41 & 48.71 & 11.46 & & & \\
\end{tabular}


Table 3. T-Test of Post Test Scores Between Group A and B

\begin{tabular}{|c|c|c|c|c|c|c|}
\hline Treatment & N & Mean & SD & df & t & Significant (2- tailed) \\
\hline Analogy (group A) & 41 & 69.71 & 10.25 & 80 & 8.66 & 0.00 \\
\hline Control (group B) & 41 & 48.71 & 11.46 & & & \\
\hline
\end{tabular}

Table 4. ANOVA Summary of Main Effects of Treatment, Cognitive Style, Gender and their Interaction Effects

\begin{tabular}{|c|c|c|c|c|c|}
\hline Source & DF & SS & MS & $\mathrm{F}$ & $\mathrm{P}$ \\
\hline TRMT & 1 & 9389.29 & 9389.29 & 82.44 & $0.00 *$ \\
\hline CST & 1 & 170.75 & 170.75 & 1.50 & 0.22 \\
\hline GND & 1 & 67.18 & 67.18 & 0.59 & 0.44 \\
\hline $\mathrm{CST}^{*} \mathrm{GND}$ & 1 & 693.96 & 693.96 & 6.09 & $0.02 *$ \\
\hline TRMT*CST & 1 & 0.25 & 0.25 & 0.00 & 0.96 \\
\hline TRMT*GNDR & 1 & 4.91 & 4.91 & 0.04 & 0.84 \\
\hline TRMT*CST*GNDR & 1 & 0.05 & 0.05 & 0.00 & 0.98 \\
\hline Error & 74 & 8428.54 & 113.90 & & \\
\hline Total & 81 & & & & \\
\hline $\begin{array}{l}\text { *= Significant at } \mathrm{P}=0 \\
\text { KEY } \\
\text { CST=cognitive Style } \\
\text { GND=Gender } \\
\text { TRMT=Treatment } \\
\text { DF=Degree of freedon } \\
\text { SS=Sum of square } \\
\text { MS=Mean squares } \\
\text { F=F-ratio } \\
\text { P=Probability }\end{array}$ & & & & & \\
\hline \multicolumn{6}{|c|}{ Table 5. Lsd Post-Hoc Comparison Test } \\
\hline GND & $\mathrm{ME}$ & & & & \\
\hline FI & 63. & & & & \\
\hline FD & 61. & & & & \\
\hline FI & 58. & & & & \\
\hline FD & 54. & & & & \\
\hline
\end{tabular}

Key: HG = Homogeneous Groups

\section{Discussion and Recommendations}

The pre-test results provided a basis on which it could be reasonably assumed that both experimental and control groups had equivalent entry knowledge at the commencement of treatment (mean scores of 10.95 and 11.31) for analogy and control groups respectively. Thus, after the treatment, results of the achievement test in physics showed that there was significant difference in the achievement of the two groups. The difference in the achievement between the two groups could be attributed to the treatment given. This is because the result shown in Table 3 indicated that there was a significant main effect of treatment on students' achievement in the physics achievement test. The group taught using analogy instructional strategy achieved higher than the group taught using lecture method. This implies that analogy instructional strategy proved to be superior over the conventional lecture method in enhancing students' achievement in physics. This agrees with the findings of [9] that the continuous use of the conventional lecture method to teach students some abstract concepts like atom, current, voltage among others reduces their ability to grasp the meaning than when they are taught using instructional strategy like analogy that builds on their preexisting ideas. Reference [8] believed that use of analogy instructional strategy by science teachers enhance students' understanding because knowledge is actively constructed by the learner on the grounds of constructs already available to him/her in the mind.

Another finding of this study is that there is no significant main effect of cognitive style on students achievement in physics. This is contrary to the findings of
$[25,26]$. They had found that students' cognitive style had influence on achievement in science related subjects. Such findings of the differential impact of cognitive style on students' achievement in science may perhaps occur as a result of the types of instructional strategies employed in teaching the subjects. Reference (15) observed that difficulty of concepts is a formed attitude which can be broken through the adoption of the most appropriate instructional strategy by the teacher. The study further found that gender had no significant main effect on students' achievement in physics. This finding is at variance with the finding of (22) that men perform better than women especially in science based subject like physics. The findings of men being superior to women may perhaps have been accentuated by gender stereotyping which is commonly based on cultural belief.

On the interaction effects of the independent variables (treatment, students' cognitive style and their gender) on the dependent variable, it was found that when students' cognitive style was crossed with gender, a significant interaction effect on the students' achievement was produced. The finding of the study also revealed that interaction effects between students' cognitive style and instructional techniques was not significant on students' achievement in PAT. Likewise the interaction effect between instructional technique and students' gender.

Least significant difference (LSD) post-hoc comparison test also revealed that field independent female students and field dependent male students were homogeneous. This showed that the achievement of FI female and FD male students in the physics achievement test was not significantly different and are superior to FI male and FD female students. This may lend credence to the common saying that what a man can do a woman can do, perhaps better. This is because, male or female, FI or FD can be intelligent or dull.

From the results of this study it can therefore be inferred that students' cognitive style and gender have little or no effects on academic achievement in physics. The most important factor which had significant effect on students' academic achievement was the instructional strategy adopted. It was therefore recommended that analogy instructional strategy should be adopted by all science teachers (especially physics teacher) to teach students some abstract or difficult concepts instead of the conventional lecture method as measure to improve achievement.

\section{References}

[1] Okoro, O.M, Principles and methods in vocation and technical tducation. University Trust Publishers, Nsuka, 2007.

[2] FRN, National Policy of Education (5 ${ }^{\text {th }}$ ed). NERDC, Abuja, 2006.

[3] Enemali, J.D, A study of mechanisms for improving effectiveness in managing of Technical Colleges in Northern State of Nigeria: Spectrum Journal, 1 (2), 12-28, 1994.

[4] Okorie, J.U, Vocational Industrial Education. League of Researchers in Nigeria (LRN), Bauchi, 2001.

[5] Adamu, G.H, Adamawa mobilizes for access to education: Weekly scope, 1-2. $6^{\text {th }}$ June 2010.

[6] Okoronka, U.A, Effect of model-based instructional strategies on students' attitude towards Physics in secondary education. 
Adamawa State University Journal of Scientific Research. 1 (1) 89-97, 2011.

[7] National Business and Technical Examination Board, Chief Examination's Report: NABTEB Head Quarter Benin, Nigeria, 2010.

[8] Glynn, S.M., Taasoobshirazi, G. and fowler, S, Analogies: Explanatory tools in web-based-science instruction Educational Technology http//www.COE.uga.edu/twa/pdf/glynn-2007article.Pdf.

[9] Novak, J.D. and Canas, A.J, The theory underlying concept maps and how to construct and use them: Technical report IHMC Camp Tools, 2008

[10] Onwuka, U, Curriculum development for Africa, Africana Fep. Publishers, Onisha, 1990.

[11] Asishana, A.S, Concept Mapping Instructional Strategy and Students’ Meaningful Learning. Nigerian Journal of Professional Teachers 1 (6), 2010.

[12] Abimbola, I,O. and Mustapha, M.T, The use of Analogies in communicating difficulty science concepts to secondary school students: The Nigeria Teachers Today: A VJournal of Teacher Education, (911). 2001

[13] Okoronka, U.A, Comparative effect of analogy, problem solving and concept mapping model-based instructional strategies on students achievement in physics. Journal of Research in science Teaching 130 (10) 1241-1257. 2009

[14] Tumba, I. and Wada, B.Z, Comparative analysis of student's performance in electrical installation practice courses taught using demonstration and discovering methods, Journal of League of Researchers in Nigeria, 8 (1). 2007.

[15] Egivu, G.N, The influence of instructional methods on students interest in learning of chemistry: Zaria Journal of studies, 1 (1), 19-24. 1997

[16] Tamier, P. and Kemp, R.F, College Students Cognitive Preference in Science. Journal of Educational Research. 60 (2), 143-152. 1976.

[17] Mc Robbie, C. L, Cognitive style and cognitive process. Science Education, 75 (2) 231-242. 1991.

[18] Okebukola, P.A.O, Forty years of intervention of the Science Teachers' Association of Nigeria (STAN) with Science Education and the road Ahead: 40 ${ }^{\text {th }}$ Conference Proceedings of STAN, 1987.
[19] Luk, S.C, The relationship between cognitive style and academic achievement: British Journal of educational Technology, 29 (2), 137-147. 1998.

[20] Okoronka, U.A, Model-based instructional strategies as determinants of student learning outcomes in secondary schoo physics in Lagos, Nigeria. An unpublished. PhD. Thesis, University of Ibadan, Ibadan, 2004.

[21] Mangvwat, B, Politics of Basic Education and gender issues. Proceeding of the $21^{\text {st }}$ annual congress of academy of education held at Abubakar Tafawa Balewa University Bauchi, $6^{\text {th }}-10^{\text {th }}$ November. 2006.

[22] Eze, R.O and Okoro, I.F, Comparative analysis of the performances of male and female student using problem-solving and expository methods of teaching: Journal of Curriculum Studies, 17 (2). 2010.

[23] Saraco, O.N, Students preference for field-independence, teacher characteristics. Educational Psychology, 11 (3-4), 323-332. 1991.

[24] Whyte, M.M., Knirk, F.G., Casey, R.J and Willard, M.L, Individualistic versus paired/cooperative computer assisted instruction: Matching instructional method with cognitive style. The journal of the Technology system 19 (4) 299-312. 1991.

[25] Fall, F, Cognitive style: A review of the major Theories and their application to information seeking in virtual Environment, 2003 http//www.personal.kent.Edu/pheasst/cognitive style GEM

[26] Onunkwo, G.I.N and Ekeh, P.U. (2005). Student's Cognitive styles and Achievement in integrated Science, 2005.

[27] Yohanna, P. and Nuhu, H.T, Application of remote sensing and GIS in revising township local and political ward map: A case study of Mubi Metropolis. Adamawa State University Journal of Scientific Research, 1 (1), 156-163. 2011

[28] Ughamadu, K.A, Interactive effect of formative testing and cognitive style on students learning outcome in senior secondary school chemistry: Unpublished Ph.D Thesis University of Ibadan, 1990.

[29] Ekwere, O.J.T Meta-cognitive instructional strategies and students' concept achievement and attitudes toward chemistry in Ibadan municipality. Unpublished $\mathrm{PhD}$ Thesis, University of Ibadan, 1998.

[30] Ige, T.A, Concept mapping and problem solving teaching strategies as determination of learning in secondary Biology in Nigeria: Unpublished Ph.D Thesis University of Ibadan, 1998. 